Note

\title{
Changes in Serum Levels of Type I Collagen-Related Proteins after Surgically Induced Menopause and Correlations with Bone Loss in the Lumbar Spine
}

\author{
TAKEHIKo YASUMIZU, YUKIHITo FUKADA AND KAZUHIKo HOSHI
}

Department of Obstetrics and Gynecology, Yamanashi Medical University, 1110 Shimokato, Tamaho, Nakakoma-gun, Yamanashi 409-3898, Japan

\begin{abstract}
The purpose of this prospective study was to characterize the changes in serum levels of two proteins produced during the synthesis and degradation of type I collagen, i.e., the carboxyterminal propeptide of type I procollagen (PICP) and the pyridinoline cross-linked carboxyterminal telopeptide of type I collagen (ICTP), respectively, after oophorectomy, and to assess the degree of correlation between changes in the serum values of these proteins and changes in bone mineral density (BMD) of the lumbar spine. Serum levels of PICP, ICTP and bone gla protein (BGP) were determined in 18 women before oophorectomy (baseline) and at 7 days, and 1, 2, 3, 6, 9 and 12 months post-oophorectomy (PO). The BMD of the lumbar spine was measured at baseline, and at 6 months and 12 months PO. ICTP had increased significantly at 7 days PO and peaked between 1 and 3 months PO. PICP and BGP had increased significantly at 2 months $P O$ and remained at high levels thereafter. The percent changes in lumbar BMD from baseline values (\% CFB) at 6 months and at 12 months PO were significantly correlated with \% CFB in ICTP, but not with \% CFB in PICP or BGP. Accordingly, bone resorption is a main determinant of bone mineral loss after oophorectomy and the change in recently-developed bone resorption markers, such as ICTP, is of clinical utility in predicting a degree of subsequent bone loss after surgical menopause.
\end{abstract}

Key words: Oophorectomy, PICP, ICTP, Bone mineral density, Correlation

(Endocrine Journal 46: 337-343, 1999)

THE serum carboxyterminal propeptide of type I procollagen (PICP) and the pyridinoline cross-linked carboxyterminal telopeptide of type I collagen (ICTP) reflect the rate of formation and degradation of type I collagen, respectively (1-3), and their performance as bone biochemical markers was found to be promising in studies using a method of bone histomorphometry (4) or calcium kinetics (5). Simultaneous determination of bone formation and resorption can therefore be made by measuring PICP and ICTP in serum specimens from the examinees.

Received: September 1, 1998

Accepted: January 13, 1999

Correspondence to: Takehiko YASUMIZU, M.D., Department of Obstetrics and Gynecology, Yamanashi Medical University, 1110 Shimokato, Tamaho, Nakakoma-gun, Yamanashi 409-3898, Japan
Most recent reports agree that serum PICP is a useful indicator of bone formation, but several authors concluded or pointed out that ICTP may not reflect such a minimum change as occurred in postmenopause, even though it may be a good marker of osteoporosis or metabolic bone disease (6-9). In a previous series of study we reassessed the clinical utility of ICTP in Japanese populations of postmenopausal women (10), as well as in postpartum women (11), and confirmed that ICTP is a sensitive and useful bone resorption marker, which strongly correlates with the change in bone density.

In this longitudinal study, we measured bone mineral density (BMD) in the lumbar spine and serum PICP, ICTP, and bone gla protein (BGP), a noncollagenous bone-related protein as well as an established bone formation marker $(12,13)$, in women in a surgically-induced postmenopausal state, 
and assessed degrees of correlation between changes in BMD and changes in the values of these serum markers. This population of women is considered a good model for observing relationships between BMD and biochemical marker levels, since a sharp and rapid increase in the rate of bone loss is known to occur after oophorectomy (14). Furthermore, changes in bone metabolism after oophorectomy have been reported in previous studies by using serum BGP levels and/or bone alkaline phosphatase activity as indices of bone formation and urinary hydroxyproline excretion and/or plasma tartrate-resistant acid phosphatase as indices of bone resorption (15, 16). The details of changes in serum PICP and ICTP in a longitudinal study, however, have never been reported.

Accordingly, the purpose of this study was 1) to characterize serum PICP and ICTP levels in women after oophorectomy, and 2) to assess the degree of correlation between changes in BMD and changes in the serum values of these biochemical markers.

\section{Subjects and methods}

\section{Subjects}

In accordance with the Helsinki II Declaration, fully informed consent was obtained from all participants. The research protocols were approved by the Ethics Committee of Yamanashi Medical University. A total of 20 premenopausal women, who wanted bilateral oophorectomy in conjunction with simple hysterectomy for the treatment of benign tumors in the bilateral ovaries and/or in the uterus, were selected as the subjects of this study from among the patients admitted to Yamanashi Medical University Hospital between January, 1995 and December, 1996. The criteria for inclusion as subjects of this study were: 1) under 50 years of age and a regular menstrual cycle, 2 ) body mass index less than 30 , 3) a high serum $17 \beta$-estradiol $\left(E_{2}\right)$ value $(\geqq 25$ $\mathrm{pg} / \mathrm{ml})$ and normal serum values for albumin $(>35$ $\mathrm{g} / \mathrm{L}$ ), alanine aminotransferase (ALT, $<40 \mathrm{U} / \mathrm{L}$ ), aspartate aminotransferase (AST, $<40 \mathrm{U} / \mathrm{L}$ ), blood urea nitrogen (BUN, $<7.0 \mathrm{mmol} / \mathrm{L}$ of urea), and creatinine $(<80 \mathrm{~mol} / \mathrm{L})$ before surgery, and 4$)$ absence of vertebral fractures or severe deformities on lumbar and thoracic spinal radiographs. During the study period, there were no restrictions on diet or physical activity. The only prohibition was against the use of drugs known to affect bone metabolism.

All participants were native Japanese, non-smokers, and ranged in age 39-46 years. All of them underwent scheduled operations under general anesthesia and without unexpected blood loss (the estimated blood loss was less than $200 \mathrm{ml}$ in all subjects), had an uneventful postoperative course, and returned to a normal life within one month after the operation, but two women withdrew from the study between 1 and 3 months after the operation, because of severe hot flushes in one patient and for personal reasons in the other. Ultimately, 18 subjects completed the study. None of them suffered diseases and/or injuries for which hospitalization was required at any time during the study period.

Venous blood was collected from all subjects between $9: 00$ and 10:00 am 2 or 3 days before oophorectomy (baseline) and at 7 days, and 1, 2, 3, 6, 9 and 12 months post-oophorectomy (PO). The serum was immediately separated by centrifugation and stored at $-40^{\circ} \mathrm{C}$ until analyzed. The BMD of the lumbar spine of all subjects was measured at baseline, and at 6 months and 12 months PO.

\section{Bone mineral measurement}

The BMD $\left(\mathrm{g} / \mathrm{cm}^{2}\right)$ of the lumbar spine (L2-L4) was measured antero-posteriorly by DXA (Hologic QDR 2000, Hologic, Inc., Waltham, Mass). Our radiologists found the coefficient of variation (CV) inherent in the equipment to be $0.28 \%$ for a spine phantom and $0.76 \%$ for healthy volunteers (17).

\section{Serum sample measurement}

PICP, ICTP, BGP, and $\mathrm{E}_{2}$ were measured in the Hachioji Laboratory, SRL Co., Ltd. (Tokyo, Japan) without any information about the subjects. A radioimmunoassay kit obtained from Orion Diagnostica (Oulunsalo, Finland) was used to determine PICP and ICTP $(1,2)$. Intact BGP was determined with a two-site immunoradiometric assay kit (18) obtained from Mitsubishi Yuka (Tokyo, Japan). $\mathrm{E}_{2}$ was measured with an RIA kit (19) obtained from Daiichi Isotope Co, Ltd. (Tokyo, Japan). The intraand interassay $\mathrm{CVs}$ determined in this laboratory were $4.2 \%$ and $5.6 \%$, respectively, for PICP, 3.9\% 
and $6.1 \%$ for ICTP, $2.9 \%$ and $7.3 \%$ for BGP, and $3.6 \%$ and $6.9 \%$ for $\mathrm{E}_{2}$. BUN, creatinine, ALT, and AST were assayed in all samples by standard methods. All assays were performed within four weeks of collecting the serum samples. The PICP/ICTP ratio was calculated according to the report of Sowers et al. (20) as a putative index of bone turnover balance.

\section{Statistical analysis}

All statistical analyses of the data were performed with SPSS program software (SPSS Inc.; Chicago, IIl). General linear model (GLM) repeated measures analysis of the sequential BMD and serum biomarker data was performed to evaluate the statistical significance of changes in each parameter. The paired $t$-test was used to compare the postoperative levels with baseline levels. The correlations between percent changes from baseline values (\% CFB) of BMD and each biochemical marker were determined by simple regression analyses. The degree of correlation is expressed by Spearman's coefficient of correlation $(\rho)$. The statistical significance of the correlations was determined by the $\mathrm{F}$ test. For statistical comparison of means, data are expressed as means \pm SD unless otherwise indicated. Statistical significance was defined as $P<0.05$.

\section{Results}

Table 1 shows the demographic data for age, parity, height, weight, body mass index, serum $\mathrm{E}_{2}$ level, and increase in body weight during the study period. The serum $\mathrm{E}_{2}$ levels of all subjects declined to less than $20 \mathrm{ng} / \mathrm{L}$ at 7 days $\mathrm{PO}$, and $\mathrm{E}_{2}$ was undetectable $(<10 \mathrm{ng} / \mathrm{L})$ at 1 month PO.

\section{Changes in lumbar BMD}

A time-dependent decrease in lumbar BMD was observed after oophorectomy in all subjects. The postoperative time course of lumbar BMD is summarized in Table 2. According to GLM analysis, the BMD values at each measurement point differed significantly $(P<0.001)$, and the percent changes during

Table 1. Demographic data regarding patient age, parity, height, weight, body mass index, and serum $E_{2}$ levels at baseline, and weight increase during the study period

$\begin{array}{lr}\text { Age }(\mathrm{yr}) & 43.0 \pm 2.1 \\ \text { Parity } & 2.2 \pm 1.3 \\ \text { Height }(\mathrm{cm}) & 154.0 \pm 4.6 \\ \text { Weight }(\mathrm{kg}) & 52.3 \pm 6.7 \\ \text { Body mass index } & 22.0 \pm 2.5 \\ \text { Serum } \mathrm{E}_{2}(\mathrm{ng} / \mathrm{L}) & 59.6 \pm 15.6 \\ \text { Weight increase during } & 1.2 \pm 1.7 \\ \quad \text { the study period }(\mathrm{kg}) & \end{array}$

Table 2. Time course of lumbar BMD $\left(\mathrm{g} / \mathrm{cm}^{2}\right)$

\begin{tabular}{lccc}
\hline & BMD $\left(\mathrm{g} / \mathrm{cm}^{2}\right)$ & $\begin{array}{l}P v s \\
\text { baseline }\end{array}$ & $\begin{array}{l}\text { Change within } \\
6 \text { months }(\%)\end{array}$ \\
\hline Baseline & $1.004 \pm 0.115$ & & \\
6 months PO & $0.950 \pm 0.113$ & $<0.001$ & $5.2 \pm 2.0^{\mathrm{a}}$ \\
12 months PO & $0.926 \pm 0.110$ & $<0.001$ & $2.5 \pm 2.3^{\mathrm{b}}$ \\
\hline
\end{tabular}

PO, post-oophorectomy; a $>$ b, $P=0.001$

Table 3. Time courses of changes in serum PICP, ICTP, and BGP

\begin{tabular}{lrcrrrrrr}
\hline & PICP $(\mu \mathrm{g} / \mathrm{L})$ & $P$ & ICTP $(\mu \mathrm{g} / \mathrm{L})$ & $P$ & PICP/ICTP & $P$ & BGP $(\mu \mathrm{g} / \mathrm{L})$ & $P$ \\
\hline Baseline & $77.0 \pm 29.0$ & & $3.3 \pm 0.7$ & & $24.6 \pm 11.0$ & & $3.8 \pm 1.9$ \\
7 days PO & $80.3 \pm 22.9$ & ns & $5.4 \pm 1.1$ & 0.002 & $15.1 \pm 4.3$ & 0.004 & $3.5 \pm 2.0$ & $\mathrm{~ns}$ \\
1 month PO & $89.6 \pm 24.7$ & $\mathrm{~ns}$ & $6.1 \pm 1.3$ & $<0.001$ & $14.2 \pm 4.8$ & 0.011 & $4.6 \pm 2.0$ & $\mathrm{~ns}$ \\
2 months PO & $99.5 \pm 30.8$ & 0.014 & $6.2 \pm 1.6$ & $<0.001$ & $16.4 \pm 5.1$ & 0.003 & $5.8 \pm 1.9$ & 0.005 \\
3 months PO & $99.5 \pm 28.0$ & 0.003 & $6.5 \pm 1.7$ & $<0.001$ & $16.4 \pm 6.1$ & $<0.001$ & $7.2 \pm 2.2$ & $<0.001$ \\
6 months PO & $117.0 \pm 31.7$ & $<0.001$ & $5.7 \pm 2.1$ & 0.001 & $21.4 \pm 6.5$ & 0.205 & $9.1 \pm 2.8$ & $<0.001$ \\
9 months PO & $116.2 \pm 31.5$ & $<0.001$ & $5.3 \pm 1.7$ & 0.004 & $23.8 \pm 10.2$ & 0.832 & $9.8 \pm 5.7$ & 0.001 \\
12 months PO & $113.6 \pm 29.5$ & $<0.001$ & $4.5 \pm 1.2$ & 0.031 & $26.1 \pm 8.2$ & 0.613 & $10.0 \pm 4.4$ & $<0.001$ \\
\hline
\end{tabular}

PO, post-oophorectomy; $P, P$ vs baseline value 
the first 6 months PO were significantly greater than during the second 6 months.

\section{Changes in serum markers of bone metabolism}

None of the postoperative samples had abnormal serum albumin, ALT, AST, BUN, or creatinine values. The time courses of changes in serum PICP, ICTP, and BGP, and the differences between their levels at different times PO and the baseline values are shown in Table 3. The changes in all of these markers over time were significant $(P<0.001)$ according to the results of GLM analysis. The time courses of the \% CFB are also shown in Figure 1. All three markers increased after surgery, but ICTP responded to oophorectomy much more rapidly than PICP and BGP. Serum ICTP was significantly increased at 7 day $P O$ over the baseline level, peaked between 1 and 3 months PO, and decreased gradually thereafter. The ICTP levels 9 and 12 months PO were higher than the baseline level, but significantly lower than between $1-3$ months PO $(P<0.025)$. Serum PICP and BGP showed similar postoperative changes, although the percent changes in BGP were more prominent. The levels of these two markers did not significantly differ from the baseline values until 2 months PO, but then increased and remained at high levels between 6 months and 12 months PO. The PICP/ICTP ratio decreased significantly until 3 months PO, but recovered to the baseline level after 6 months PO.

\section{Correlations between lumbar BMD and biochemi- cal markers}

Table 4 displays the Spearman rank correlations between \% CFBs in lumbar BMD at 6 and 12 months PO and \% CFBs in PICP, ICTP, PICP/ICTP, and BGP at $1,2,3,6,9$, and 12 months PO. The $\%$ CFBs in lumbar BMD at 6 months PO was negatively and significantly correlated with \% CFBs in ICTP at 3 and 6 months $\mathrm{PO}$ and the \% CFBs in lumbar BMD at 12 months $P O$ was also negatively and significantly correlated with \% CFBs in ICTP at 9 and 12 months PO. The best correlation point was the 6-month value in ICTP for the 6-month value in BMD and the 9-month value in ICTP for the 12-month value in BMD. The \% CFBs in other markers, including

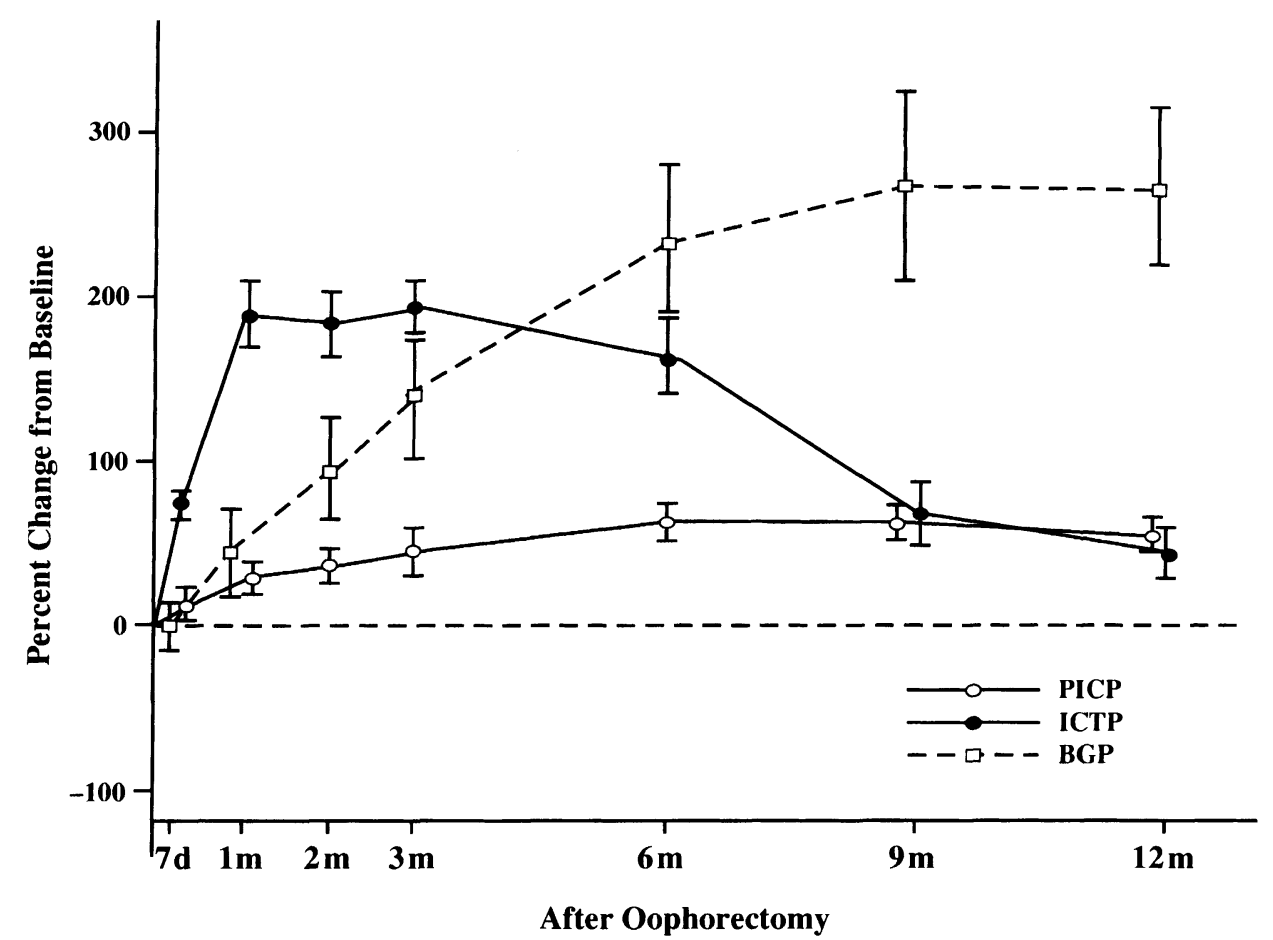

Fig. 1. Time course of percent changes in serum PICP, ICTP and BGP from the baseline. The values shown are means \pm SE. $\mathrm{d}$, days; $\mathrm{m}$, months. 
Table 4. Spearman rank correlations $(\rho)$ between the percent change (from baseline to 1, 2, 3, 6, 9 and 12 months PO) in PICP, ICTP and BGP and the percent change in lumber BMD (from baseline to 6 and 12 months PO)

\begin{tabular}{lrcc}
\hline & Months PO & 6 months & 12 months \\
\hline PICP & 1 & -0.350 & -0.418 \\
& 2 & -0.188 & -0.294 \\
& 3 & -0.176 & -0.209 \\
6 & -0.297 & 0.335 \\
ICTP & & & 0.241 \\
& & & 0.388 \\
& 1 & -0.238 & -0.238 \\
PICP/ICTP & 2 & -0.280 & -0.159 \\
& 3 & $-0.500^{\mathrm{a}}$ & -0.441 \\
& 6 & $-0.556^{\mathrm{a}}$ & -0.376 \\
& 9 & & $-0.674^{\mathrm{b}}$ \\
& 12 & & $-0.588^{\mathrm{a}}$ \\
& 2 & 0.053 & -0.059 \\
$\mathrm{BGP}$ & 3 & 0.174 & 0.026 \\
& 6 & 0.321 & 0.282 \\
& 9 & 0.462 & 0.271 \\
& 12 & & 0.312 \\
& 1 & & 0.138 \\
& 2 & 0.056 & 0.015 \\
& 3 & -0.009 & 0.159 \\
& 6 & -0.171 & -0.163 \\
& & & 0.253 \\
& & & 0.121 \\
\hline
\end{tabular}

PO, post-oophorectomy;

a, correlations are significant at $P<0.05$

b, correlations are significant at $P<0.005$

$\mathrm{PICP} / \mathrm{ICTP}$, at any measuring point did not correlate significantly with \% CFBs in BMD at 6 months or at 12 months PO.

\section{Discussion}

In this longitudinal study, we demonstrated details of the time course of serum PICP and ICTP during the first year after surgical menopause. To the best of our knowledge, this is the first report that documents the changes in both serum PICP and ICTP, type I collagen-related markers that reflect opposite events, after surgical menopause. The results of this study also demonstrate a significantly high correlation between the changes in lumbar BMD and the changes in ICTP

The serum levels of the markers measured in this study are reportedly influenced by renal and hepatic insufficiency $(2,21,22)$. Surgery can affect both renal and hepatic function. We therefore examined the hepatic and renal function of all of the participants. The samples were collected within a specified time, since circadian rhythms have been reported for all three biomarkers $(23,24)$. The possibility that the postoperative increase in ICTP may reflect the release of uterine collagen due to surgical manipulation should be considered, but this effect on postoperative ICTP levels may be small, since the postoperative levels of PICP, a type I collagen-related protein the same as ICTP, were not significantly different from the preoperative level.

The increase in bone resorption markers preceding the increase in bone formation markers is consistent with the results of earlier cross-sectional studies (2528 ) and longitudinal studies with biochemical markers other than PICP and ICTP $(15,16)$, and this finding supports the general concept that the loss of skeletal balance shortly after acute estrogen deficiency is due to the prevalence of bone resorption over new bone deposition (29). Our results, however, clearly demonstrated a gradual decline in bone resorption after 6 months PO. This phenomenon was confirmed by evidence showing that the percent changes in lumbar BMD during the first 6 months PO were significantly greater than during the second 6 months. Although the authors of the earlier studies had reported a clear difference between the percent changes in BMD during the first 6 months $P O$ and the second 6 months PO $(16,26)$, they could not explain the difference by the changes in the levels of the biochemical markers they determined. The results obtained in this study were attributed to our study design, which applied a longitudinal approach and used ICTP.

Among the biochemical markers examined, only the change in ICTP was correlated significantly with the change in BMD. This means that bone resorption is a main determinant of bone loss in healthy women. We obtained the same results in a previous study in a population of healthy postmenopausal women on hormone replacement therapy (10). The absence of any correlation between changes in bone formation markers and BMD implies that bone formation is a secondary event. Nevertheless, the 
difference between the points at which the best correlation between \% CFBs in ICTP and those in BMD were observed (the 6-month value in ICTP for the 6-month value in BMD and the 9-month value in ICTP for the 12-month value in BMD) suggests that the change in bone resorption markers is not the sole determinant of loss of BMD. Although the PICP/ICTP ratio, a putative index of bone turnover balance, was not correlated with the changes in $\mathrm{BMD}$, it might be theoretically possible to obtain a better arithmetic parameter by using the PICP and ICTP values to predict later changes in BMD.

In conclusion, this study clearly demonstrates differences in the time course of the bone resorption marker, ICTP, and the bone formation markers, PICP and BGP, after oophorectomy, and that they were reflected by the difference in the percentage decrease in BMD between the first and second 6month periods PO. This study also demonstrates significantly high correlations between \% CFBs in lumbar BMD and \% CFBs in ICTP. These results indicate that bone resorption is a main determinant of bone mineral loss after oophorectomy and that \% CFBs in recently-developed bone resorption markers, such as ICTP, is of clinical utility in predicting a degree of subsequent bone loss after surgical menopause.

\section{Acknowledgments}

We are grateful to Diagnostica Division, Chugai Pharmaceutical Co., Ltd. (Tokyo) and Hachiouji Laboratory, SRL Co., Ltd. (Tokyo) for their cooperation in the measurement of PICP, ICTP and BGP. The present study was supported in part by Grants-in-Aid 06671635 and 08671878 provided by the Ministry of Education, Science and Culture of Japan.

\section{References}

1. Meikko J, Niemi S, Risteli J (1990) Radioimmunoassay of the carboxy-terminal propeptide of human type I procollagen. Clin Chem 36: 1328-1332.

2. Risteli J, Elomaa I, Niemi S, Novamo A, Risteli L (1993) Radioimmunoassay for the pyridinoline crosslinked carboxyl terminal telopeptide of type I collagen: a new serum marker of bone collagen degradation. Clin Chem 39: 635-640.

3. Robey PG, Fisher LW, Young MF, Termine JD (1988) The biochemistry of bone. In: Riggs BL, Melton LJ III (eds) Osteoporosis. Raven Press, New York, pp 445-468.

4. Eriksen EF, Charles P, Melsen F, Mosekilde L, Risteli L, Risteli J (1993) Serum markers of type I collagen formation and degradation in metabolic bone disease: correlation with bone histomorphometry. J Bone Miner Res 8: 127-132.

5. Charles P, Mosekilde L, Risteli L, Risteli J, Eriksen EF (1994) Assessment of bone remodeling using biochemical indicators of type I collagen synthesis and degradation: relation to calcium kinetics. Bone Miner 24: 81-94.

6. Prestwood KM, Pilbeam CC, Burleson JA, Woodiel FN, Delmas PD, Deftos LJ, Raisz LG (1994) The short term effects of conjugated estrogen on bone turnover in older women. J Clin Endocrinol Metab 79: $366-371$.

7. Garnero P, Shih WJ, Gineyts E, Karpf DB, Delmas
PD (1994) Comparison of new biochemical markers of bone turnover in late postmenopausal osteoporotic women in response to alendronate treatment. J Clin Endocrinol Metab 79: 1693-1700.

8. Kushida K, Takahashi M, Kawana K, Inoue T (1995) Comparison of markers for bone formation and resorption in premenopausal and postmenopausal subjects, and osteoporosis patients. J Clin Endocrinol Metab 80: 2447-2450.

9. Hassager C, Jensen LT, P $\phi$ denphant J, Thomsen K, Christiansen C (1994) The carboxyl-terminal pyridinoline cross-linked telopeptide of type I collagen in serum as a marker of bone resorption: the effect of nandrolone decanoate and hormone replacement therapy. Calcif Tissue Int 54: 30-33.

10. Yasumizu T, Hoshi K, Iijima S, Asaka A (1998) Serum concentration of carboxyl terminal cross-linked telopeptide of type I collagen (ICTP) is a useful indicator for decline and recovery of bone mineral density in lumbar spine: analysis in Japanese postmenopausal women with or without hormone replacement. Endocr J 45: 45-51.

11. Yasumizu T, Nakamura $Y$, Hoshi $K$, lijima S, Asaka A (1998) Bone metabolism after human parturition and the effect of lactation: longitudinal analysis of serum bone-related proteins and bone mineral content of lumbar spine. Endocr $J$ 45: 679-686.

12. Deftos LJ (1991) Bone protein and peptide assays in 
the diagnosis and management of skeletal disease. Clin Chem 37: 1143-1148.

13. Johansen JS, Riis BJ, Delmas PD Christiansen C (1988) Plasma BGP: an indicator of spontaneous bone loss and of the effect of oestrogen treatment in Postmenopausal women. Eur J Cin Invest 18: 191195.

14. Duursma SA, Rayamker JA, Boereboom FTJ, Scheven BAA (1991) Estrogen and bone metabolism. Obstet Gynecol Survey 47: 38-44.

15. Gambacciani M, Spinetti A, Cappagli B, Taponeco F, Felipetto R, Parrini D, Cappelli N, Fioretti P (1993) Effects of ipriflavone administration on bone mass and metabolism in ovariectomized women. J. Endocrinol Invest 16: 333-337.

16. Štěpán J. J, Pospíchal J, Schreiber V, Kaňka J, Menšík J, Presl J, Pacovský V (1989) The applicatio of plasma tartrate-resistant acid phosphatase to assess changes in bone resorption in response to artificial menopause and its treatment with estrogen or norethisterone. Calcif Tissue Int 45: 273-280.

17. Koizumi K, Uchiyama G, Araki T, Hihara T, Ogata H, Monzawa S (1990) Fundamental evaluation of bone densitometry using dual energy X-ray absorptiometry (DEXA). Nippon Acta Radiologica 50: 123129. (in Japanese).

18. Masters PW, Jones RG, Purves DA, Coooper EH, Cooney JM (1994) Commercial assays for serum osteocalcin give clinically discordant results. Clin Chem 40: 358-363.

19. Suzuki A, Ohara A, Yasui T, Mori K, Mori T (1984) Fundamental and clinical investigation of the estradiol direct radioimmunoassay kit. Clinical Endocrinol 33: 627-632. (in Japanese)

20. Sowers MF, Eyre D, Hollis BW, Randolph JF, Shapiro B, Jannausch ML, Crutchfield M (1994) Biochemical markers of bone turnover in lactating and nonlactating postpartum women. J Clin Endo- crinol Metab 80: 2210-2216.

21. Smedsr d B, Melkko J, Risteli L, Risteri J (1990) Circulating C-terminal propeptide of type I procollagen is cleared mainly via the mannose receptor in liver endothelial cells. Biochem J 271: 345-350.

22. Gundberg CM, Hauschka PV, Lian JB, Gallop PM (1972) Osteocalcin: Isolation, characterization and detection. Methods Enzymol 107: 516-521.

23. Gundberg CM, Markowitz ME, Mizruchi M, Rosen JF (1985) Osteocalcin in human serum: A circadian rhythm. J Clin Endocrinol Metab 60: 736-739.

24. Hassager C, Risteli J, Risteli L, Jensen SB, Christiansen C (1992) Diurnal variation in serum markers of type I collagen synthesis and degradation in healthy premenopausal women. J Bone Miner Res 7: 1307-1311.

25. Hashimoto K, Nozaki M, Yokoyama M, Sano M, Nakano H (1994) Urinary excretion of pyridinium crosslinks of collagen in oophorectomized women as markers for bone resorption. Maturitus 18: 135-142.

26. Mazzuoli G, Minisola S, Bianchi G, Pacitti MT, Rosso R, Romagnoli E, Carnevale V, Scarnecchia L, Celi FS, Ortore V, Carenza L (1990) The effects of oophorectomy on skeletal metabolism. J Steroid Biochem Molec Biol 37: 457-459.

27. Ohta H, Makita K, Suda Y, Ikeda T, Matsuzawa T, Nozawa S (1992) Influences of oophorectomy on serum levels of sex steroid and bone metabolism and assessment of bone mineral density in lumbar trabecular bone by QCT-C value. J Bone Miner Res 7: 659-665.

28. Štěpán JJ, Pospíchal J, Presl J, Pacovský V (1987) Bone loss and biochemical indices of bone remodeling in surgically induced postmenopausal women. Bone 8: 279-284.

29. Horowitz MC(1993) Cytokines and estrogen in bone: anti-osteoporotic effects. Science 260: 626-627. 